$\underline{\text { ARTIGO }}$

\title{
A FORMAÇÃO CONTINUADA DE PROFESSORES DA EDUCAÇÃO SUPERIOR: UM ESTUDO DAS LEGISLAÇÕES NACIONAIS
}

\author{
CONTINUING EDUCATION OF HIGHER EDUCATION TEACHERS: A STUDY OF NATIONAL
}

LEGISLATION

\section{LA FORMACIÓN CONTINUA DE PROFESORES DE EDUCACIÓN SUPERIOR: UN ESTUDIO DE LAS LEGISLACIONES NACIONALES}

\author{
Altair Alberto Fávero \\ Universidade de Passo Fundo - Brasil \\ Lidiane Limana Puiati Pagliarin \\ Universidade Federal da Fronteira Sul - Brasil
}

Resumo: O objetivo do presente texto é analisar legislações nacionais que sugerem a responsabilidade das instituições de educação superior federais em planejar e desenvolver ações de formação continuada aos seus docentes. Trata-se de uma pesquisa qualitativa quanto à abordagem do problema, exploratória quanto ao objetivo e documental quanto aos procedimentos. A discussão está ancorada em AlvaradoPrada, Freitas e Freitas (2010), Behrens (2007), Pachane (2006), Pimenta e Anastasiou (2003), Soares e Cunha (2010), dentre outros. O artigo é composto por duas partes. A primeira apresenta os principais aspectos das referidas leis e a segunda analisa os pontos que podem repercutir em promoção de formação continuada para docentes do magistério superior. A análise da legislação nacional indicou tímida discussão sobre a docência e seus saberes nos cursos de mestrado e doutorado; enfoque dos cursos stricto sensu na pesquisa; escassas estratégias que garantam implementação de política de desenvolvimento de pessoal para professores de magistério superior, embora o desenvolvimento profissional desses professores seja bastante considerado em políticas externas de avaliação da educação superior. Em síntese, não há política nacional de formação continuada para docentes universitários, porém, há legislação que obriga as instituições federais de educação superior a ofertar política de desenvolvimento de pessoal em nível de capacitações - não de formação continuada - para técnicos-administrativos e docentes.

Palavras chave: Formação continuada; Legislação nacional; Professor de magistério superior.

Abstract: The purpose of this text is to analyze national legislation that suggest the responsibility of the federal higher education institutions in planning and developing continuing education actions for their teachers. It is a qualitative research regarding the approach to the problem, exploratory as to the objective and documentary as to the procedures. The discussion is anchored in Alvarado-Prada, Freitas e Freitas (2010), Behrens (2007), Pachane (2006), Pimenta and Anastasiou (2003), Soares and Cunha (2010), among others. The article consists of two parts. The first presents the main aspects of the aforementioned laws and the second analyzes the points that may have repercussions in promoting continuing education for teachers in higher education. The analysis of national legislation indicated a timid discussion about 
teaching and its knowledge in master's and doctoral courses; focus of stricto sensu courses on research; few strategies to guarantee the implementation of personnel development policy for higher education teachers, although the professional development of these teachers are widely considered in external policies for the evaluation of higher education. In summary, there is no national policy of continuing education for university teachers, however, there is legislation that obligates federal institutions of higher education to offer personnel development policy at the level of training - not continuing education - for technical-administrative and teachers.

Keywords: Continuing education; National legislation; Higher education teachers

Resumen: El propósito de este texto es analizar las legislaciones nacionales que sugieren la responsabilidad de las instituciones federales de educación superior en planificar y desarrollar acciones de educación continua para sus maestros. Es una investigación cualitativa cuanto el enfoque del problema, exploratoria cuanto al objetivo y documental cuanto a los procedimientos. La discusión está anclada en Alvarado-Prada, Freitas e Freitas (2010), Behrens (2007), Pachane (2006), Pimenta y Anastasiou (2003), Soares y Cunha (2010), entre otros. El artículo consta de dos partes. El primero presenta los aspectos principales de las legislaciones antes mencionadas y el segundo analiza los puntos que pueden tener repercusiones en la promoción de la educación continua para los docentes de educación superior. El análisis de la legislación nacional indicó una discusión tímida sobre la enseñanza y su conocimiento en los cursos de maestría y doctorado; enfoque de los cursos estrictos sobre investigación; Existen pocas estrategias para garantizar la implementación de la política de desarrollo del personal para los docentes de educación superior, aunque el desarrollo profesional de estos docentes se considera ampliamente en las políticas externas para la evaluación de la educación superior. En resumen, no existe una política nacional para la educación continua de los docentes universitarios, sin embargo, existe una legislación que exige que las instituciones federales de educación superior ofrezcan una política de desarrollo del personal a nivel de capacitación - no educación continua - para técnicos administrativos y docentes.

Palabras clave: Educación continua; Legislación nacional; Profesor de enseñanza superior.

\section{Introdução}

No início do século XXI a educação superior brasileira vivenciou uma considerável expansão tanto em relação ao número de matrículas quanto à infraestrutura. Em decorrência disso, proporcionou uma ampliação no acesso a cursos superiores para populações pouco vistas nas universidades até então. O Programa Universidade para Todos (PROUNI ${ }^{1}$ ), criado pela Lei n. 11.096, de 13 de janeiro de 2005 e o Programa de Apoio a Planos de Reestruturação e Expansão das Universidades Federais (REUNI), instituído pelo Decreto nº 6.096, de 24 de abril de 2007, foram políticas que garantiram essa expansão da educação superior brasileira.

O REUNI, em especial, foi responsável pela expansão física da rede federal de educação superior no país. Em consequência disso, houve também um aumento no número de professores

\footnotetext{
${ }^{1}$ PROUNI é um programa do Ministério da Educação que oferece bolsas de estudo a estudantes de instituições particulares de educação superior, em cursos de graduação e sequenciais de formação específica.
} 
ingressantes na carreira de magistério superior e, ao mesmo tempo, um alargamento de suas funções, abrangendo não somente o ensino, a pesquisa e a extensão, mas também a gestão de programas relacionados à educação.

Diante desse cenário, a educação superior tornou-se fértil campo de estudos e pesquisas, com inúmeros focos, dentre eles, a docência universitária. Discutia-se sobre o professor de magistério superior, seus saberes, suas metodologias de ensino, formas e critérios de ingresso para trabalho na educação superior. Também se percebia a necessidade de acompanhar os docentes que estavam ingressando por meio de concursos e processos seletivos para atuação nesse nível de ensino. Além disso, apontava-se para a necessidade de formação continuada para todos os docentes, independentemente do tempo de serviço na instituição.

Essas demandas foram percebidas porque os cursos de pós-graduação no Brasil, especialmente mestrados e doutorados acadêmicos, desde sua implantação na década de 1960, se configuram formalmente como responsáveis pela formação do professor para atuar na educação superior. Porém, seus currículos enfatizam a formação do pesquisador e isentam-se na formação para a docência. A formação dos professores universitários é uma questão secundária nos programas de pós-graduação, inclusive os da área da educação (SOARES; CUNHA, 2010).

Além disso, quando existe alguma formação para a docência no magistério superior em cursos Stricto sensu, essa geralmente fica restrita a uma disciplina, tendo um espaço pequeno de estudos e discussões diante da complexidade dessa profissão. Isso corrobora a afirmação de que a formação do professor universitário fica focada em disciplinas de cunho teórico, voltadas à linha ao qual o mestrando ou doutorando faz parte, ou então, focada na pesquisa (PIMENTA; ANASTASIOU, 2003).

Essas constatações justificam a necessidade de uma formação continuada para professores de magistério superior. Ademais, a expansão da educação superior, bem como as mudanças da sociedade nos últimos anos também fundamentam a necessidade de haver formação continuada desses docentes e, mais do que isso, que as ações de formação continuada estejam organizadas em forma de política educacional.

No entanto, passados alguns anos dessa expansão², a literatura da área (MELO, 2018; EVANGELISTA; FERREIRA, 2018; TORRES; ALMEIDA, 2013) afirma que na atual

\footnotetext{
${ }^{2}$ A partir de 2016 a educação superior teve novos contornos, principalmente após a homologação da Emenda Constitucional n. 95/2016 (BRASIL, 2016) e desde então vem sofrendo drásticos cortes orçamentários que atingem desde a expansão em relação à infraestrutura (finalização de obras) até a permanência dos alunos nos cursos de graduação e de pós-graduação. Para Dutra e Brisolla (2020), tal Emenda adiou a criação de novos cursos e a contratação de recursos humanos, assim como houve diminuição de financiamento de pesquisas, por exemplo.
} 
legislação brasileira não há indicação de obrigatoriedade de formação continuada para professores de magistério superior, assim como não há uma política ou programa formativo dessa natureza em âmbito nacional.

Apesar de não haver programa ou política nacional sobre a formação continuada para professores de magistério superior, entende-se que na legislação educacional brasileira pode haver indicativos que essa formação precisa acontecer. Assim, torna-se importante problematizar: como a legislação nacional trata a formação continuada de docentes de magistério superior? Diante dessa questão, o objetivo do presente texto é analisar legislações nacionais que sugerem a responsabilidade das instituições de educação superior federais em planejar e desenvolver ações de formação continuada aos seus docentes.

Trata-se de uma pesquisa qualitativa quanto à abordagem do problema, exploratória quanto ao objetivo e documental quanto aos procedimentos. As fontes de informação utilizadas para essa pesquisa referem-se a documentos: Lei de Diretrizes e Bases da Educação Nacional (n. 9394 de 20 de dezembro de 1996), Lei que regulamenta o Sistema Nacional de Avaliação da Educação Superior (n. 10.861, de 14 de abril de 2004), Decretos que instituem a política e as diretrizes para o desenvolvimento de pessoal da administração pública federal (decretos $\mathrm{n}$. 5.707, de 23 de fevereiro de 2006; n. 5.825, de 29 de junho de 2006), leis que orientam sobre o Estágio de Docência oferecido em cursos de mestrado e doutorado (portarias n.16, de 14 de abril de 2010; n. 181, de 10 de dezembro de 2012), Plano Nacional de Pós-Graduação (PNPG 2011-2020), Plano Nacional de Educação (lei n. 13.005, de 25 de junho de 2014) e decreto que altera a política nacional de desenvolvimento de pessoas (n. 9.991, de 28 de agosto de 2019). O texto é composto por duas partes, sendo a primeira uma apresentação dos principais aspectos das referidas leis e a segunda uma análise desses principais pontos que podem repercutir em promoção de formação continuada para docentes de magistério superior.

\section{Legislações nacionais que podem reverberar em orientações sobre a formação continuada de professores de magistério superior}

Nesta seção são apresentadas as principais legislações educacionais que podem implicar na formação continuada de professores de magistério superior da rede federal. Tais documentos são apresentados de forma cronológica, iniciando pela Lei de Diretrizes e Bases da Educação Educacional n. 9.394/96 e finalizando com o Decreto ${ }^{\circ}$ 9.991, de 28 de agosto de 2019.

Ao analisar a atual legislação brasileira é possível perceber que a titulação é quesito importante para a seleção de docentes para atuar na educação superior. Não há uma legislação específica sobre o tema, porém, de acordo com a Lei de Diretrizes e Bases da Educação 
Nacional (BRASIL, 1996), artigo 52, pelo menos um terço do corpo docente precisa apresentar titulação acadêmica de mestrado ou doutorado, assim como pelo menos um terço do corpo docente precisa trabalhar em regime de tempo integral na instituição. A lei, em seu artigo 54, também garante autonomia para que as universidades possam planejar o quadro de pessoal para atuar na instituição, de maneira a "atender às peculiaridades de sua estrutura, organização e financiamento pelo Poder Público, assim como dos seus planos de carreira e do regime jurídico do seu pessoal" (BRASIL, 1996, art. 54).

Além disso, a mesma legislação define que "a preparação para o exercício do magistério superior far-se-á em nível de pós-graduação, prioritariamente em programas de mestrado e doutorado" (BRASIL, 1996, art. 66) e que os profissionais da educação terão ingresso "exclusivamente por concurso público de provas e títulos" (art. 67, I). Nesse sentido, pode-se afirmar que nessa legislação não há critérios para ingresso na carreira de magistério superior além de apresentar diploma de pós-graduação e passar por seleção de provas e títulos. Ou seja, não menciona a obrigatoriedade de formação específica para a docência, já que mestrados e doutorados priorizam a formação para a pesquisa.

Outro documento que repercute na formação continuada de docentes é a lei 10.861, que institui o Sistema Nacional de Avaliação da Educação Superior (SINAES), homologada em 14 de abril de 2004. Esse sistema observa três componentes: a avaliação das instituições, dos cursos e do desempenho dos estudantes. Seu documento informa que a avaliação da educação superior considera diferentes dimensões institucionais, dentre elas: "as políticas de pessoal, as carreiras do corpo docente e do corpo técnico-administrativo, seu aperfeiçoamento, desenvolvimento profissional e suas condições de trabalho" (BRASIL, 2004a, art 3º, V).

Desse modo, percebe-se que o documento que regulamenta o SINAES observa, dentre outros aspectos, as políticas de desenvolvimento profissional dos que atuam na universidade, bem como outras questões inerentes ao trabalho docente na instituição (perfil, carreira e condições de trabalho). É através desse sistema, em seus diversos instrumentos de avaliação, que são atribuídos conceitos aos cursos e às instituições de educação superior, implicando em autorização e reconhecimento de cursos, bem como de expansão das Instituições de Educação Superior (IES). Portanto, a legislação do SINAES oferece elementos para que as IES invistam em processos de desenvolvimento profissional dos docentes da educação superior.

Outro item avaliado pelo SINAES é o Plano de Desenvolvimento Institucional de cada IES. Trata-se de um documento que a Lei 10.861, de 14 de abril de 2004 apenas cita, mas não explicita elementos para sua composição. Nesse sentido, em dezembro de 2004 foi lançado o documento "Plano de Desenvolvimento Institucional - PDI: Diretrizes para Elaboração" 
(BRASIL, 2004b). Nele estão descritos os eixos temáticos essenciais do PDI, dentre eles, a Gestão Institucional, formada por organização administrativa, organização e gestão de pessoal e políticas de atendimento discente. Na organização e gestão de pessoal o documento orienta descrever sobre: a) corpo docente: composição, políticas de qualificação, regime de trabalho e plano de carreira; b) plano e cronograma de expansão do corpo docente, especificando titulação e regime de trabalho, bem como perfil existente e pretendido; e c) corpo técnico-administrativo: políticas de qualificação, plano de carreira e/ou cargos e salários, além de cronograma de expansão (BRASIL, 2004b).

Em 2006, dois decretos sobre gestão e desenvolvimento de pessoal são publicados: Decreto $^{\circ}$ 5.707, de 23 de fevereiro de 2006 (BRASIL, 2006a) e Decreto $n^{\circ} 5.825$, de 29 de junho de 2006 (BRASIL, 2006b) $^{3}$. O primeiro institui a Política e as Diretrizes para o Desenvolvimento de Pessoal da administração pública federal direta, autárquica e fundacional, bem como regulamenta dispositivos da Lei no 8.112, de 11 de dezembro de 1990 (que dispõe sobre o regime jurídico dos servidores públicos civis da União, das autarquias e das fundações públicas federais). A referida política tem como finalidade:

I - melhoria da eficiência, eficácia e qualidade dos serviços públicos prestados ao cidadão;

II - desenvolvimento permanente do servidor público;

III - adequação das competências requeridas dos servidores aos objetivos das instituições, tendo como referência o plano plurianual;

IV - divulgação e gerenciamento das ações de capacitação; e

V - racionalização e efetividade dos gastos com capacitação (BRASIL, 2006a, art. 1).

Nesse sentido, as IES, ao proporem sua política de desenvolvimento de pessoal precisam observar tais finalidades. Percebe-se que os termos "desenvolvimento permanente", "competências" e "capacitação" são elementos-chave para guiar a construção das políticas nas IES. O artigo 2 da referida legislação destaca as concepções de capacitação, gestão por competência e eventos de capacitação. A capacitação é entendida como "processo permanente e deliberado de aprendizagem, com o propósito de contribuir para o desenvolvimento de competências institucionais por meio do desenvolvimento de competências individuais". A gestão por competências é vista como "gestão da capacitação orientada para o desenvolvimento do conjunto de conhecimentos, habilidades e atitudes necessárias ao desempenho das funções dos servidores, visando ao alcance dos objetivos da instituição" e os eventos de capacitação são

\footnotetext{
${ }^{3}$ Esses decretos foram revogados em agosto de 2019, dando lugar ao Decreto $\mathrm{n}^{\circ}$ 9.991, de 28 de agosto de 2019 e à Instrução Normativa $n^{\circ} 201$, de 11 de setembro de 2019, os quais entraram em vigor em 2020. No entanto, a análise dos decretos revogados é apresentada aqui porque foram leis importantes para construir certa cultura de “desenvolvimento de pessoal” nas IES públicas até meados de 2019.
} 
"cursos presenciais e à distância, aprendizagem em serviço, grupos formais de estudos, intercâmbios, estágios, seminários e congressos, que contribuam para o desenvolvimento do servidor e que atendam aos interesses da administração pública federal" (BRASIL, 2006a, art.2). Além disso, há a descrição do que a legislação entende por educação continuada: "oferta regular de cursos para o aprimoramento profissional, ao longo de sua vida funcional" (BRASIL, 2006a, art. 3).

As diretrizes da política de desenvolvimento de pessoal incluem termos como "competências institucionais e individuais", "capacitação interna ou externamente ao seu local de trabalho", "qualificação para o exercício de atividades de direção e assessoramento", "aproveitamento de habilidades e conhecimentos de servidores de seu próprio quadro de pessoal”, "educação continuada", "atividades de capacitação como requisito para a promoção funcional do servidor", "cursos introdutórios ou de formação (...) aos servidores que ingressarem no setor público", "avaliar permanentemente os resultados das ações de capacitação", "elaborar o plano anual de capacitação da instituição, compreendendo as definições dos temas e as metodologias de capacitação", "ampla divulgação das oportunidades de capacitação", "priorizar, no caso de eventos externos de aprendizagem, os cursos ofertados pelas escolas de governo" (BRASIL, 2006a, art. 3).

Por fim, o referido decreto estabelece que as instituições precisam elaborar um plano anual de capacitação, um relatório das ações efetivamente realizadas e ter um sistema de gestão por competências. O Comitê Gestor da Política Nacional de Desenvolvimento de Pessoal tem como uma das funções avaliar os relatórios anuais dos órgãos e entidades (BRASIL, 2006a).

O segundo decreto publicado no mesmo ano - Decreto ${ }^{\circ} 5.825$, de 29 de junho de 2006 (BRASIL, 2006b) - estabelece as diretrizes para elaboração do Plano de Desenvolvimento dos Integrantes do Plano de Carreira dos Cargos Técnico-Administrativos em Educação. Apesar do conteúdo desse decreto não estar diretamente relacionado a essa pesquisa por tratar especificamente da carreira de técnicos-administrativos, faz-se importante ressaltar que não há um decreto especificamente para os docentes públicos federais, apenas para cargos técnicosadministrativos. Destaca-se também que o documento expõe alguns conceitos importantes a serem contemplados na política de desenvolvimento dos servidores das IES. Dentre eles, destacam-se: aperfeiçoamento: "processo de aprendizagem, baseado em ações de ensinoaprendizagem, que atualiza, aprofunda conhecimentos e complementa a formação profissional do servidor, com o objetivo de torná-lo apto a desenvolver suas atividades, tendo em vista as inovações conceituais, metodológicas e tecnológicas" e qualificação: "processo de aprendizagem baseado em ações de educação formal, por meio do qual o servidor adquire 
conhecimentos e habilidades, tendo em vista o planejamento institucional e o desenvolvimento do servidor na carreira" (BRASIL, 2006b, art. 3).

Nessas duas resoluções é possível perceber uma orientação conceitual para as IES no que se refere à política de "desenvolvimento de pessoal". A capacitação, o aperfeiçoamento e a qualificação são termos recorrentes em ambos os decretos. Seus conceitos partem sempre da ideia de aprendizagem como processo. As resoluções pouco utilizam o termo formação, mas sim capacitação, que se refere tanto a ações de educação formal (cursos de especialização, mestrado e doutorado) quanto das diversas ações formativas promovidas interna ou externamente à IES que auxiliem na sua atuação profissional, seja como docente, seja como técnico-administrativo.

Outro documento importante para essa discussão refere-se ao Plano Nacional de PósGraduação, homologado em 2010, para a década 2011-2020. Com objetivo de definir diretrizes, estratégias e metas para política de pós-graduação e pesquisa no Brasil, apresenta, em dois volumes, o contexto da pós-graduação no país, bem como projeções para a década em vigência. O Plano parte de um contexto que o país vivia em 2010, de acelerada economia com projeções bastante positivas para a próxima década: "O país entrou no século XXI como uma nova potência emergente, com a perspectiva de tornar-se a quinta economia do planeta no decênio 2011-2020” (CAPES, 2010, p. 16). Assim, afirma que em decorrência disso, o país passaria por profundas mudanças na economia e em outras áreas, impactando na educação superior.

Dessa forma, o Plano propõe-se a "favorecer a integração do ensino de pós-graduação com o setor empresarial e a sociedade" (p. 17), afirma que "O núcleo da pós-graduação é a pesquisa" e que "a parceria entre a Universidade, o Estado e as empresas dará lugar ao chamado modelo da tríplice hélice" (CAPES, 2010, p. 18). A ideia que transversaliza os dois volumes do documento é que a pós-graduação possui foco na pesquisa em áreas emergentes (tecnologias, engenharias etc).

A docência é citada no documento quando se refere à relação com a educação básica. No documento ficam claros os objetivos de estreitamento das relações da CAPES com a educação básica, mediante programas como Observatório da Educação, Programa de Consolidação das Licenciaturas (PRODOCÊNCIA), Programa Institucional de Bolsas de Iniciação à Docência (PIBID), Universidade Aberta do Brasil (UAB), Plano Nacional de Formação dos Professores da Educação Básica (PARFOR). No entanto, a CAPES se coloca à disposição de melhorar a educação básica e a formação dos professores que nela atuam, mas não destaca como a educação básica pode auxiliar na pós-graduação. Ou seja, parece ser uma via de mão simples, 
da CAPES para a educação básica, e não de mão dupla onde a educação básica possa dialogar com a CAPES e com a pós-graduação no sentido de auxiliá-la no processo de formação.

Apesar do documento afirmar que ao longo de sua trajetória, a CAPES atuou para "cumprir metas de capacitação de recursos humanos para a docência acadêmica e apoio à formação de pesquisadores para as instituições brasileiras" (CAPES, 2010, p. 283), a docência no magistério superior ainda é citada no documento de forma vaga e tímida. Ou seja, fica claro que essa não é a prioridade da CAPES. Como o próprio plano cita, seu núcleo é a pesquisa.

É preciso destacar que os programas de pós-graduação ofertam a disciplina Estágio de Docência, porém, segundo a legislação, ela é obrigatória apenas aos bolsistas de programas do MEC/CAPES. Tanto a Portaria n. 76, de 14 de abril de 2010 (CAPES, 2010, art. 18), que concede bolsas de mestrado e doutorado para estudantes de IES públicas - CAPES/DS, quanto a Portaria n. 181, de 18 de dezembro de 2012, que dispõe de bolsas de mestrado e doutorado para estudantes de IES particulares - CAPES/PROSUP (CAPES, 2012, art. 20), possuem a mesma redação sobre o Estágio de Docência, conforme descrição a seguir: "O Estágio de Docência é parte integrante da formação do pós-graduando, objetivando a preparação para a docência, e a qualificação do ensino de graduação". Os documentos ainda garantem que tal estágio é obrigatório para todos os bolsistas e possui carga horária máxima de 04 horas semanais por no mínimo um semestre (no caso de bolsistas PROSUP) ou dois semestres (no caso de Bolsistas DS).

O atual PNE (BRASIL, 2014), homologado em 2014, com vigência de 10 anos, é outro documento importante para demarcar políticas de formação docente tanto para atuação na educação básica quanto na educação superior. Uma das diretrizes do PNE refere-se à "valorização dos(as) profissionais da educação" (art.2, IX), o que sugere o desenvolvimento de políticas de formação para os profissionais da educação. No que se refere à pós-graduação, a meta e as estratégias alinham-se ao Plano Nacional de Pós-Graduação, anteriormente analisado, principalmente no que se refere à expansão da pós-graduação stricto sensu tanto nas diversas regiões do país quanto pela sua internacionalização. A meta do PNE é "elevar gradualmente o número de matrículas na pós-graduação stricto sensu, de modo a atingir a titulação anual de 60.000 (sessenta mil) mestres e 25.000 (vinte e cinco mil) doutores" (BRASIL, 2014, meta 14).

Em relação à educação superior, o plano prevê a expansão de universidades e institutos:

[...] elevar a taxa bruta de matrícula na educação superior para 50\% (cinquenta por cento) e a taxa líquida para $33 \%$ (trinta e três por cento) da população de 18 (dezoito) a 24 (vinte e quatro) anos, assegurada a qualidade da oferta e expansão para, pelo menos, $40 \%$ (quarenta por cento) das novas matrículas, no segmento público. (BRASIL, 2014, meta 12). 
No entanto, nenhuma estratégia correspondente a essa meta menciona objetivos referentes ao trabalho do professor ou sua formação para atender toda essa expansão. Importante destacar que se há expansão de cursos e programas no âmbito das universidades, o trabalho do professor sofre alterações - e, muitas vezes, precarizações, seja por ter de atender um público maior nas atividades de ensino, pesquisa e extensão, seja para atender de forma individualizada os alunos, por exemplo. Além disso, a expansão da educação superior trouxe para dentro das IES estudantes de grupos sociais diversos, oriundos de escolas públicas e particulares de diferentes regiões do país, carregando consigo trajetórias escolares diversas. Para incluir toda essa diversidade na instituição, o professor exerce papel importante e, nesse sentido, precisa ser percebido como agente desse processo, com condições de trabalho e de formação permanente.

A meta seguinte almeja "elevar a qualidade da educação superior e ampliar a proporção de mestres e doutores do corpo docente em efetivo exercício no conjunto do sistema de educação superior para 75\% (setenta e cinco por cento), sendo, do total, no mínimo, 35\% (trinta e cinco por cento) doutores" (BRASIL, 2014, meta 13). Assim, percebe-se que o Plano prevê ampliação do número de mestres e doutores. Destaca-se o ponto positivo dessa meta, ao preocupar-se com a titulação de professores, porém, como defendido anteriormente, cursos de mestrado e doutorado hoje enfatizam formação para a pesquisa e não para a docência.

Em suas estratégias da Meta 13, percebe-se alguns indicativos em relação aos professores de magistério superior, como por exemplo, a autoavaliação das IES, "destacando-se a qualificação e a dedicação do corpo docente" (estratégia 13.3). No entanto, são sugestões tímidas que não deixam explícita a importância de políticas de formação continuada para os professores que atuam na educação superior. Ademais, ao se referir à formação continuada de profissionais da educação superior, apenas projeta "promover a formação inicial e continuada dos (as) profissionais técnico-administrativos da educação superior” (BRASIL, 2014, estratégia 13.9). Ou seja, os professores de magistério superior não estão contemplados nessa estratégia do PNE.

Por fim, destaca-se a Meta 18 do PNE que garante plano de carreira para profissionais de todos os níveis da educação: "assegurar, no prazo de 2 (dois) anos, a existência de planos de Carreira para os (as) profissionais da educação básica e superior pública de todos os sistemas de ensino (...)”. Importante ressaltar uma das estratégias para atingir tal meta:

[...] implantar, nas redes públicas de educação básica e superior, acompanhamento dos profissionais iniciantes, supervisionados por equipe de profissionais experientes, a fim de fundamentar, com base em avaliação 
documentada, a decisão pela efetivação após o estágio probatório e oferecer, durante esse período, curso de aprofundamento de estudos na área de atuação do (a) professor (a), com destaque para os conteúdos a serem ensinados e as metodologias de ensino de cada disciplina. (BRASIL, 2014, estratégia 18.2).

Em 28 de agosto de 2019 foi publicado o Decreto nº 9.991 (BRASIL, 2019a), que dispõe sobre a Política Nacional de Desenvolvimento de Pessoas da administração pública federal direta, autárquica e fundacional, e regulamenta dispositivos da Lei ${ }^{\circ}$ 8.112, de 11 de dezembro de 1990, quanto a licenças e afastamentos para ações de desenvolvimento. Tal decreto revoga o Decreto $n^{\circ} 5.707$, de 23 de fevereiro de 2006, anteriormente citado nesta seção. O referido documento mantém a obrigatoriedade de as IES proporem plano e relatório anuais de ações de desenvolvimento de pessoas, os quais deverão ser aprovados pelo órgão central do Sistema de Pessoal Civil da Administração Federal (SIPEC), que poderá requerer informações e alterações sobre o conteúdo do plano. Além disso, indica a unidade de gestão de pessoas do órgão ou da entidade como responsável pela proposição do plano e do relatório e colocar em caráter obrigatório o levantamento de necessidades de desenvolvimento dos servidores. O decreto restringe o número de servidores para licença para capacitação em $2 \%$ : “o quantitativo previsto pelo órgão ou pela entidade não poderá ser superior a dois por cento dos servidores em exercício no órgão ou na entidade" (BRASIL, 2019a, art. 27, parágrafo único).

Logo em seguida é publicada a Instrução Normativa n ${ }^{\circ}$ 201, de 11 de setembro de 2019 (BRASIL, 2019b), que dispõe sobre os critérios e procedimentos específicos para a implementação da Política Nacional de Desenvolvimento de Pessoas, de que trata o Decreto $n^{\circ}$ 9.991, de 28 de agosto de 2019, pelos órgãos integrantes do Sistema de Pessoal Civil da Administração Federal - SIPEC. Nesse documento há a explicitação da concepção de ação de desenvolvimento ou capacitação: "toda e qualquer ação voltada para o desenvolvimento de competências, organizada de maneira formal, realizada de modo individual ou coletivo, presencial ou a distância, com supervisão, orientação ou tutoria" (BRASIL, 2019b, art. 2, I). Assim, a descrição de "processo permanente" explicitado no entendimento do mesmo termo nos decretos $n^{\circ} 5.707$ (BRASIL, 2006a, art. 2) e n 5.825 (BRASIL, 2006b, art. 3) é suprimida, deixando o conceito vago, já que defende que a capacitação seja toda e qualquer ação. Na seção seguinte é apresentada análise dos principais aspectos das leis anteriormente citadas.

\section{Legislações nacionais para a formação continuada de professores de magistério superior: em busca de uma política educacional}

Após a apresentação dos principais aspectos de legislações nacionais que podem reverberar em ações de formação continuada para docentes de magistério superior, analisa-se 
como elas podem contribuir para uma política nacional de formação continuada para esses docentes. Inicialmente é preciso destacar a ausência de políticas de formação específica para ingresso na carreira docente. A Lei de Diretrizes e Bases da Educação Nacional faz algumas sinalizações a respeito do ingresso na carreira, mas ainda deixa para que cada IES elabore critérios de seleção de docentes.

Essa ausência de políticas é corroborada por um "pensamento hegemônico, uma desconsideração da dimensão científica da docência, como se o trabalho docente fosse uma consequência natural do conhecimento geral que possuem os professores" (MELO, 2018, p. 26). Ou, ainda, a ausência de políticas reflete a visão da docência como dom - e que, portanto, não precisa haver formação para tal - ou o entendimento que ao saber o conteúdo de sua área, saberá ensinar, pensamento esse que desvaloriza os saberes do campo pedagógico.

Dessa falta de clareza sobre a natureza do trabalho docente e seus saberes, não raramente os termos "capacitação" e "formação" são utilizados como sinônimos. Para Zabalza (2004, p. 38), de maneira geral, produziu-se um vazio de significado à ideia de formação, pois ela é definida, muitas vezes, "mais pelo que se ofertou ou pelo tipo de produto externo que se quer obter do que pelo efeito real que ela exercerá sobre as pessoas que se beneficiam dela". Para ele, a ideia de formação pode ficar empobrecida se for reduzida à mera aquisição de informações novas, ao desenvolvimento de uma habilidade ou à obtenção de aprendizagens acadêmicas imediatistas. A formação precisa estar atrelada ao crescimento e aperfeiçoamento das pessoas, em sentido global, envolvendo o desenvolvimento profissional e pessoal dos sujeitos.

Logo, formação não pode ser sinônimo de treinamento ou de capacitação. Behrens (2007) lembra que os termos capacitação ou treinamento foram utilizados por muitos anos quando se tinha um modelo conservador de educação e tornou-se influente a partir do século XVIII. Depois, "na década de setenta no século XX, o treinamento veio atender ao modelo Fordista de produção e visou preparar profissionais para executar uma determinada tarefa por meio de modelagem" (p. 442, grifos da autora). A capacitação também era utilizada como sinônimo da qualificação profissional, entendida como repetição de tarefas para preparação de pessoal para determinada técnica ou manejo. Surgiu na indústria, mas a escola também utilizou tal modelo. Por isso,

Denominações do tipo capacitação, treinamento, reciclagem e aperfeiçoamento, entre outras, correspondem a uma ideologia e uma concepção tecnicista da educação que apresentam preocupação com a eficácia e a eficiência na educação tal como acontece na indústria, no comércio e no mercado de capitais cujo foco principal é apenas o lucro (ALVARADOPRADA; FREITAS; FREITAS, 2010, p. 374-375). 
Ademais, tais termos contribuem para o desenvolvimento de cursos de curta duração, palestras, ações esporádicas e implementação de "pacotes" prontos, com ações predefinidas externamente à instituição da qual o professor faz parte. Como consequência, "os professores são considerados apenas consumidores de conhecimentos ou executores de tarefas e não autores dentro do processo educativo, nem gestores da sua própria aprendizagem" (ALVARADOPRADA; FREITAS; FREITAS, 2010, p. 375).

Nesse sentido, Alvarado-Prada, Freitas e Freitas (2010) defendem que as políticas de formação docente precisam deixar claro suas concepções, suas justificativas e seus objetivos. Além disso, as políticas precisam conferir e criar mecanismos de autonomia aos professores para a construção de conhecimentos. Essa autonomia não é construída de maneira instantânea, mas faz-se importante para o próprio desenvolvimento profissional docente.

Ao analisar os decretos que tratam da política de desenvolvimento de pessoal de servidores da esfera federal, percebe-se certa confusão de termos (no caso das legislações de 2006) e certo esvaziamento de conceitos (nas legislações de 2009). Nessas legislações, o termo utilizado é a capacitação, apontada como um processo permanente, confundindo-se com o conceito de formação. Essa diferenciação é importante para traçar os objetivos, as estratégias e as metas para uma possível formação continuada de professores.

Também se destaca a importância e a natureza do trabalho docente na educação superior. A formação continuada para professores em serviço é apontada ainda como um desafio tanto para as IES quanto para os próprios docentes. Há dilemas quanto a concepções de formação continuada e também resistência por parte de professores. No entanto, ela se torna necessária na medida em que, conforme afirmam Soares e Cunha (2010) e Pimenta e Anastasiou (2003), no Brasil a pós-graduação se configura como responsável pela formação do professor para atuar na educação superior, mas há muitas lacunas nos cursos de mestrado e doutorado em relação à formação para a docência.

Mediante análise do Plano Nacional de Pós-Graduação para a década 2011-2020 ficou evidente que uma dessas lacunas é que a pós-graduação brasileira está voltada para a pesquisa. Nesse sentido, é importante destacar preocupação em relação a essa constatação, pois além de pesquisador, o professor de magistério superior precisa dedicar-se à docência, ou seja, precisa desenvolver diversos saberes, que incluem aspectos das ciências da educação, não somente de sua área específica. As legislações sobre estágio de docência no âmbito de cursos de mestrado e doutorado obriga apenas bolsistas dos programas de pós-graduação a terem essa experiência.

De acordo com Pachane (2006, p. 98), essa organização curricular dos cursos de pósgraduação reproduz, mesmo sem a intenção, "uma situação em que atividades de ensino e 
pesquisa são realizadas de modo dissociado, ou mesmo equivocado, e por perpetuar a noção de que para ser professor basta conhecer a fundo determinado conteúdo e, no caso específico do ensino superior, ser um bom pesquisador”. Nessa discussão, Soares e Cunha (2010, p. 93) são enfáticas ao afirmar que é "um equívoco pensar que os saberes da pesquisa se transferem mecanicamente para os saberes do ensino. A pesquisa, embora fundamental no processo formativo, não é suficiente para assegurar a qualidade da docência universitária". As autoras defendem que para haver mediação entre o ensino e a pesquisa é indispensável os saberes do campo pedagógico.

Nesse sentido, uma revisão curricular dos cursos de pós-graduação pode ser mostrar promissora, a fim de estreitar a relação entre ensino e pesquisa. Porém, é preciso ter a sensibilidade e o

[...] cuidado para que não se instituam nas universidades programas obrigatórios de formação pedagógica dos pós-graduandos somente com a finalidade de cumprir determinações legais, constituindo-se apenas num apêndice de um curso de pós-graduação, sem integração com as demais atividades realizadas no mesmo e sem ligação com a prática, limitando-se à apresentação de algumas poucas teorias educacionais ou mesmo, ao oferecimento de algumas técnicas de condução de aulas, sem reflexão mais ampla sobre a educação superior. (PACHANE, 2006, p. 99).

$\mathrm{O}$ atual PNE avança no sentido de propor o acompanhamento de professores em início de carreira, de modo a aprofundar conhecimentos referentes a conteúdos de ensino e metodologias para o processo de ensino e aprendizagem. Tal estratégia é de fundamental importância tanto para professores iniciantes na educação básica quanto iniciantes na educação superior. Como apontam Gaeta e Masetto (2013), esses professores enfrentam dúvidas, expectativas, ansiedades tanto em relação ao domínio de conteúdos específicos quanto (e principalmente) em relação à dimensão pedagógica, às metodologias de ensino, ao processo de ensino e aprendizagem. É preciso, portanto, de um olhar mais atento aos professores, pois a valorização profissional perpassa pela qualidade da formação, tanto da inicial quanto da formação ao longo da carreira.

No entanto, apesar de a educação superior brasileira ter avançado em legislações sobre o tema desde a expansão desse nível de ensino, percebe-se que o desenvolvimento de políticas nesse sentido recai sobre cada instituição. Conforme aponta Selbach (2015, p. 106), "a estruturação das políticas institucionais de desenvolvimento profissional docente seguem diferentes processos, repercutindo em formas ímpares de organização". As IES, com poucas referências para a constituição de uma política própria para essa finalidade e até falta de 
profissionais para a responsabilidade dessa formação, acabam sendo morosas, muitas vezes, no processo de elaboração de uma proposta consistente e que atenda as demandas locais.

É importante ressaltar que as IES possuem obrigação, de acordo com os decretos anteriormente citados, por desenvolver uma política de desenvolvimento de pessoal, a qual inclui tanto pessoas ocupantes de cargos técnico-administrativos quanto cargos de docente. No entanto, pela natureza e especificidade de cada cargo, é significativo que as istituições desenvolvam ações amplas que contemplem a formação permanente de todos os servidores, mas também é importante fortalecer ações direcionadas, pois docentes e técnicoadministrativos possuem demandas de trabalho e formação distintas. Além disso, ações isoladas podem atender a legislação, mas não se caracterizam em uma política de formação. Para a constituição de uma política institucional, de acordo com Pagliarin (2020), é preciso haver um conjunto de medidas com concepções e objetivos definidos, com ações planejadas, desenvolvidas e avaliadas periodicamente e, além disso, que tais ações tenham continuidade e aprofundamento.

Cabe ressaltar que a formação docente é um processo constante e, portanto, não pode ser confundido com titulação. Além disso, "o processo para tornar-se professor deve ser construído durante a longa trajetória da história profissional de cada um. É um processo lento, contínuo, permanente e deve ter como critério principal o compromisso individual e institucional para esse fim” (MARCELO GARCIA; PRYJMA, 2013, p. 40).

Ainda, de acordo com Gaeta e Masetto, "não é um curso ou uma vivência isolada que transformará o professor em docente profissional". Por ser uma "atividade multifacetada", a docência "implica interação de conhecimento, atividades, estrutura, recursos e que envolve estudantes, professores, coordenadores de ensino, pessoal administrativo, empresários, pais e, em última instância, o governo por meio das políticas públicas". A docência compõe-se de vários contextos, elementos e atores, ou seja, "é na interação do professor com todos esses atores e com as variadas oportunidades de formação que tiver que a profissão docente será socialmente construída" (GAETA; MASETTO, 2013, p. 107-108).

Por isso, tornar-se professor (e tornar-se professor da educação superior) não é uma habilidade adquirida somente pela aprovação em concurso de provas e títulos, mas uma construção contínua e, o mais importante, é uma construção coletiva. Isso sinaliza a importância das IES promoverem espaços e momentos de reflexão coletiva sobre a docência, bem como ações permanentes, uma vez que a docência é um processo contínuo de (re)construção. Como afirma Zabalza (2004, p. 28), a formação é um "processo contínuo ao longo da vida". 
Portanto, de acordo com Torres e Almeida (2013, p. 19), relacionar a formação do professor da educação superior com o seu desenvolvimento profissional significa:

[...] reconstruir os significados da sua ação profissional, investir na profissão docente e nos seus saberes, estabelecer uma formação relacionada aos vários momentos da trajetória e da carreira profissional, possibilitar a criação de espaços e de lugares de debate para a construção da identidade do professor, no plano individual e coletivo, investir na dimensão coletiva a fim de evitar o isolamento dos professores e estimulá-los a compreender a docência como um compromisso político e, por fim, debater as perspectivas de formação como processo sistemático com acompanhamento, envolvendo os professores desde o planejamento até a discussão pública de seus resultados, superando o entrave das descontinuidades administrativas.

Esse é o desafio, de acordo com as autoras supracitadas. Ou seja, relacionar a pedagogia, a educação superior e a formação de professores e aliá-los ao seu desenvolvimento profissional em programas institucionais, sendo que esses precisam estar alinhados a projetos pessoais e profissionais de professores de diversas áreas torna-se algo difícil de se realizar, mas, ao mesmo tempo, necessário. Para Torres e Almeida (2013,p. 20), "essa é uma possibilidade profícua para o enfrentamento dos desafios e mudanças da educação superior no atual contexto".

Em síntese, pode-se considerar que as políticas institucionais de formação docente para atuação na educação superior possuem grande potencial, uma vez que vários documentos legais nacionais citam o desenvolvimento profissional como algo que as IES precisam levar em consideração no seu planejamento. Além disso, é potente porque os professores já estão em atuação, conseguem perceber suas dificuldades e desafios profissionais e, portanto, podem realizar seu processo formativo no seu lócus de trabalho. No entanto, para se constituir em política, é preciso planejamento, desenvolvimento e avaliação das ações que, pela natureza das políticas, precisam estar articuladas e com objetivos claros.

\section{Considerações finais}

O texto teve como objetivo analisar legislações nacionais que sugerem a responsabilidade das instituições de educação superior federais em planejar e desenvolver ações de formação continuada aos seus docentes. Em síntese, pode-se afirmar que mediante leitura e análise de documentos oficiais nacionais referentes à educação (legislações que orientam sobre o Estágio de Docência oferecido em cursos de mestrado e doutorado, Lei de Diretrizes e Bases da Educação Nacional, Lei que regulamenta o Sistema Nacional de Avaliação da Educação Superior, Decretos que instituem a política e as diretrizes para o desenvolvimento de pessoal da administração pública federal, Plano Nacional de Pós-Graduação e Plano Nacional de 
Educação) percebe-se que há algumas orientações sobre "capacitação" para servidores que atuam em instituições de educação superior.

Dentre as orientações, destacam-se: tímida discussão sobre a docência e seus saberes nos cursos de mestrado e doutorado; regulação de que o ingresso na carreira de magistério superior dar-se-á por provas e títulos (preferencialmente com mestrado ou doutorado), mas as IES possuem autonomia para elaborar critérios de seleção; enfoque dos cursos stricto sensu na pesquisa, inclusive deixando essa posição clara em documento orientador da pós-graduação; escassas estratégias que garantam implementação de política de formação continuada para professores de magistério superior, embora o desenvolvimento profissional desses professores seja bastante considerado em políticas externas de avaliação da educação superior.

Os dois decretos publicados em 2006, a saber, Decreto $\mathrm{n}^{\circ} 5.707$, de 23 de fevereiro de 2006 (BRASIL, 2006a) e Decreto n 5.825, de 29 de junho de 2006 (BRASIL, 2006b), que dispunham sobre política e diretrizes para desenvolvimento de pessoal de servidores de instituição pública e federal foram marcos essenciais para o planejamento e desenvolvimento de ações de "capacitação", denominação utilizada pelos próprios documentos. Atualmente, as IES estão em processo de adaptação à nova instrução normativa, fruto do Decreto ${ }^{\circ}$ 9.991, de 28 de agosto de 2019 (BRASIL, 2019a), o qual dispõe sobre a nova Política Nacional de Desenvolvimento de Pessoas em âmbito dos servidores federais, incluindo os docentes das IES dessa natureza jurídica.

Importante destacar que mesmo que não haja um programa nacional de formação continuada para professores de magistério superior, alguns documentos oficiais nacionais oferecem indicativos de sua importância e alguns deles deixam clara a responsabilidade das IES pelo planejamento de ações dessa natureza. Dessa maneira, pode-se afirmar que não há um programa nacional de formação continuada para docentes de magistério superior, porém, podese afirmar que perante as legislações vigentes, as IES necessitam ter uma "política de desenvolvimento de pessoas", que inclua técnico-administrativos e professores. As formas de planejamento, desenvolvimento, bem como conteúdos e metodologias dessas ações não são tratados nos documentos e, portanto, são de responsabilidade de cada instituição.

Assim, as IES não só podem desenvolver políticas institucionais para seus servidores pela autonomia universitária que a legislação lhes garante, como também essas IES estão respaldadas pelos documentos anteriormente citados. Trata-se, portanto, de as IES estarem sensíveis para, juntamente com seus docentes, planejar e desenvolver ações formativas efetivas e permanentes para o desenvolvimento profissional docente, não somente para cumprir uma demanda da legislação, mas para a formação daqueles que auxiliam a construir a universidade. 
Em síntese, conclui-se que, como mostra a literatura apresentada, não há uma política nacional de formação continuada para docentes que atuam na educação superior. Porém, ficou evidente que, apesar de não haver tal política, há legislações que obrigam as IES públicas federais a desenvolver uma política de desenvolvimento de pessoal. Assim, não há uma política nacional, mas é preciso, por força da lei, haver políticas institucionais para docentes e técnicosadministrativos.

As legislações apontam para políticas institucionais em nível de "capacitações", não em nível de uma formação continuada. Conforme já discutido neste texto, a capacitação é sinônimo de uma concepção tecnicista de educação, voltada para a qualificação profissional imediatista e de reprodução de práticas sem autoria e sem reflexão sobre sua ação pedagógica. Desse modo, faz-se necessário fortalecer o movimento em prol de uma política nacional que balize ações de formação continuada - entendida como processo amplo e complexo que oportuniza o protagonismo das ações docentes, em um movimento constante de (re)pensar a ação pedagógica - e construir uma cultura institucional de formação continuada docente.

\section{REFERÊNCIAS}

ALVARADO-PRADA, Luis; FREITAS, Thais; FREITAS, Cinara. Formação continuada de professores: alguns conceitos, interesses, necessidades e propostas. Rev. Diálogo

Educacional, Curitiba, v. 10, p. 367-387, 2010.

BEHRENS, Marilda. O paradigma da complexidade na formação e no desenvolvimento profissional de professores universitários. Educação, Porto Alegre, v. 30, n. 63, p. 439-455, 2007.

BRASIL. Lei n. 9.394, de 20 de dezembro de 1996. Estabelece as diretrizes e bases da educação nacional. MEC. Brasília, 1996.

BRASIL. Lei 10.861, de 14 de abril de 2004. Institui o Sistema Nacional de Avaliação da Educação Superior - SINAES e dá outras providências. MEC. Brasília, 2004a. Disponivel em: <http://www.planalto.gov.br/ccivil_03/_ato2004-2006/2004/lei/110.861.htm>. Acesso em: 04 set. 2018.

BRASIL. Plano de Desenvolvimento Institucional - PDI: Diretrizes para Elaboração. Brasília. MEC. Brasília, 2004b.

BRASIL. Decreto n ${ }^{\circ}$ 5.707, de 23 de fevereiro de 2006 - Institui a Política e as Diretrizes para o Desenvolvimento de Pessoal da administração pública federal direta, autárquica e fundacional, e regulamenta dispositivos da Lei no 8.112, de 11 de dezembro de 1990. MEC. Brasília, 2006a. 
BRASIL. Decreto $n^{\circ} 5.825$, de 29 de junho de 2006 - Estabelece as diretrizes para elaboração do Plano de Desenvolvimento dos Integrantes do Plano de Carreira dos Cargos TécnicoAdministrativos em Educação, instituído pela Lei no 11.091, de 12 de janeiro de 2005. MEC. Brasília, 2006b.

BRASIL. Decreto n ${ }^{\circ}$ 5.773, de 09 de maio de 2006. Dispõe sobre o exercício das funções de regulação, supervisão e avaliação de instituições de educação superior e cursos superiores de graduação e sequenciais no sistema federal de ensino. MEC. Brasília, 2006c.

BRASIL. Lei n. 13.005, de 25 de junho de 2014 - Aprova o Plano Nacional de Educação PNE e dá outras providências. MEC. Brasília, 2014.

BRASIL. Emenda Constitucional n. 95, de 15 de dezembro de 2016. Altera o Ato das Disposições Constitucionais Transitórias, para instituir o Novo Regime Fiscal, e dá outras providências. Diário Oficial da União, Brasília, 16 dez. 2016.

BRASIL. Decreto n 9.991, de 28 de agosto de 2019. MEC. Brasília, 2019a.

BRASIL. Instrução normativa no 201, de 11 de setembro de 2019. MEC. Brasília, 2019b.

CAPES. Plano Nacional de Pós-Graduação - PNPG 2011-2020. MEC. Brasília, 2010.

CAPES. Portaria CAPES n.16, de 14 de abril de 2010 - Regulamento do Programa de Demansa Social DS. MEC. Brasília, 2010.

CAPES. Portaria n. 181, de 10 de dezembro de 2012 - Regulamento do Programa de Suporte à Pós-Graduação de Instituições de Ensino Particulares. MEC. Brasília, 2012.

DUTRA, Norivan; BRISOLLA, Lívia. Impactos e rupturas na educação superior brasileira após a Emenda Constitucional 95/2016: o caso dos institutos federais. FINEDUCA - Revista de Financiamento da Educação, v. 10, n. 7, p. 1-17, 2020.

EVANGELISTA, Izabel; FERREIRA, Maria. Por onde caminha a docência universitária? Curitiba: CRV, 2018.

GAETA, Cecília; MASETTO, Marcos. O professor iniciante no ensino superior: aprender, atuar e inovar. São Paulo: Senac, 2013.

MARCELO GARIA, Carlos; PRYJMA, Marielda. A aprendizagem docente e os programas de desenvolvimento profissional. In: PRYJMA, Marielda. Desafios e trajetórias para o desenvolvimento profissional docente. Curitiba: Editora UTFPR, 2013. p. 37-53.

MELO, Geovana. Pedagogia universitária: aprender a profissão, profissionalizar a docência. Curitiba: CRV, 2018.

PACHANE, Graziela. Teoria e prática na formação de professores universitários: elementos para discussão. In: RISTOFF, Dilvo; SEVEGNANI, Palmira. Docência na educação

superior. Brasília: Instituto Nacional de Estudos e Pesquisas Educacionais Anísio Teixeira, v. 5; Série Educação Superior em Debate, 2006. p. 97-145. 
PAGLIARIN, Lidiane. O desenvolvimento profissional docente de professores de magistério superior: reverberações e contribuições das políticas institucionais de formação continuada. 211f. Tese (Doutorado em Educação). Universidade de Passo Fundo, Passo Fundo, 2020. Orientador: Prof. Dr. Altair Alberto Fávero.

PIMENTA, Selma; ANASTASIOU, Lea. Docência no Ensino Superior. São Paulo: Cortez, 2003.

SELBACH, Paula. Desenvolvimento profissional docente em tempos de expansão da educação superior: o movimento nas universidades federais do Rio Grande do Sul. 220f. Tese (Doutorado em Educação). Universidade Federal do Rio Grande do Sul, Porto Alegre, 2015. Orientadora: Profa. Dra. Maria Beatriz Luce.

SOARES, Sandra; CUNHA, Maria Isabel. Formação do professor: a docência universitária em busca de legitimidade. Salvador: EDUFBA, 2010.

TORRES, Alda; ALMEIDA, Maria. Formação de professores e suas relações com a pedagogia para a educação superior. Formação docente, Belo Horizonte, v. 05, n. 09, p. 1122, 2013.

ZABALZA, Miguel. O ensino universitário: seu cenário e seus protagonistas. Tradução Ernani Rosa. Porto Alegre: Artmed, 2004.

\title{
SOBRE OS AUTORES:
}

\begin{abstract}
Altair Alberto Fávero
Possui Pós-Doutorado (Bolsista Capes) pela Universidad Autónoma del Estado de México (UAEMéx), Doutorado em Educação (UFRGS), Mestre em Filosofia do Conhecimento (PUC/RS), Especialista em Epistemologia das Ciências Sociais (UPF) e Graduado em Filosofia (UPF). Atua como professor e pesquisador no Curso de Filosofia e no Programa de PósGraduação em Educação - Mestrado e Doutorado - da UPF. Líder do Grupo de Estudos e Pesquisas em Educação Superior (GEPES/UPF). E-mail: altairfavero@ gmail.com

(iD) https://orcid.org/0000-0002-9187-7283
\end{abstract}

\section{Lidiane Limana Puiati Pagliarin}

Doutora em Educação (UPF), Mestre em Educação (UFSM) e Licenciada em Pedagogia (UFSM). Atua como professora em cursos de licenciatura da Universidade Federal da Fronteira Sul - campus Erechim-RS; membro do Grupo de Estudos e Pesquisas em Educação Superior (GEPES/UPF). E-mail: lidianepuiatipagliarin@gmail.com

(iD https://orcid.org/0000-0002-5390-5167

Recebido em: 12 de maio de 2020 Aprovado em: 16 de dezembro de 2020 Publicado em: 01 de fevereiro de 2021 